\title{
Synthesis and Study of Physicochemical Properties of New Substituted Tetrathieno[2,3-b]porphyrazines
}

\author{
Tatiana V. Dubinina, ${ }^{\mathrm{a}, \mathrm{b} @ ~ D a r i a ~ V . ~ D y u m a e v a, ~}{ }^{a}$ Stanislav A. Trashin, ${ }^{\mathrm{b}}$ Marina V. \\ Sedova, ${ }^{\mathrm{c}}$ Alexey B. Karpo, ${ }^{\mathrm{d}}$ Vitaly I. Krasovskii, ${ }^{\mathrm{d}}$ and Larisa G. Tomilova ${ }^{\mathrm{a}, \mathrm{b}}$ \\ a'Department of Chemistry, M.V. Lomonosov Moscow State University, 119991 Moscow, Russian Federation \\ ${ }^{\mathrm{b}}$ Institute of Physiologically Active Compounds, Russian Academy of Sciences, 142432 Chernogolovka, Moscow Region, \\ Russian Federation \\ 'Institute for Theoretical and Applied Electromagnetics, Russian Academy of Sciences, 125412 Moscow, Russian Federation \\ ${ }^{\mathrm{d}}$ A.M. Prokhorov Institute of General Physics, Russian Academy of Sciences, 119991 Moscow, Russian Federation \\ ${ }^{\circledR}$ Corresponding author E-mail: dubinina.t.vid@gmail.com
}

\begin{abstract}
Synthetic approach to a new substituted tetrathieno[2,3-b]porphyrazine, its planar and sandwich-type complexes was developed. Aggregation phenomena and spectral properties of the target compounds were investigated by UVVis spectroscopy and AFM. Electrochemical behaviour of the Zn complex was studied in a wide range of potentials $(-2.0 \div 2.0 \mathrm{~V})$. The $N L O$ properties of Zn complex was studied by the z-scan approach.
\end{abstract}

Keywords: Porphyrazines, nonlinear optical properties, electrochemistry, sandwich-type complexes, UV-Vis spectroscopy.

\section{Introduction}

Tetrathieno[2,3-b]porphyrazines are the less studied analogues of phthalocyanines. ${ }^{[1]}$ The presence of a sulphur-containing heterocyclic moiety in the macrocycle improves photoconductivity ${ }^{[2]}$ and nonlinear optical (NLO) properties. $^{[3]}$ Therefore such compounds are of importance for a range of functional applications including photovoltaic cells, ${ }^{[2 \mathrm{~b}]}$ photodynamic therapy $(\mathrm{PDT}),{ }^{[4]}$ and optical data storage devices. ${ }^{[5]}$ Previously reported unsubstituted tetrathieno[2,3-b]porphyrazines exhibit low solubility in organic solvents, and the synthetic strategy is inefficient (yield $\leq 16 \%$ ). ${ }^{[6]}$ Synthesis of alkoxy-substituted porphyrazines is also of low yield (15-20\%) and includes a complicated synthesis of initial dinitrile. ${ }^{[2 a]}$ The present paper focuses on the synthesis of highly-soluble substituted tetrathieno[2,3- $b]$ porphyrazines and investigation of spectral and electrochemical properties.

\section{Experimental}

Column chromatography was carried out on neutral MNAluminiumoxid. Preparative TLC was performed using Merck Aluminium Oxide $\mathrm{F}_{254}$ neutral flexible plates. The electrolyte $\left[\mathrm{Bu}_{4} \mathrm{~N}\right]^{+}\left[\mathrm{BF}_{4}\right]^{-}$(Sigma-Aldrich) was recrystallized twice from ethyl acetate/hexane $(9: 1, \mathrm{~V} / \mathrm{V})$ and dried under vacuum at $70{ }^{\circ} \mathrm{C}$. $o$-Dichlorobenzene (DCB, 99\%, Sigma-Aldrich, HPLC-grade) for voltammetric and specrtoelectrochemical studies was used as received. All other reagents and solvents were obtained or distilled according to standard procedures. The salts $\mathrm{Mg}(\mathrm{OAc})_{2} \cdot 4 \mathrm{H}_{2} \mathrm{O}$; $\mathrm{Zn}(\mathrm{OAc})_{2} \cdot 4 \mathrm{H}_{2} \mathrm{O} ; \mathrm{Lu}(\mathrm{OAc})_{3} \cdot 4 \mathrm{H}_{2} \mathrm{O}$ was dried immediately before use in a vacuum desiccator for $4 \mathrm{~h}$ at $90^{\circ} \mathrm{C}$. All reactions were TLC and $\mathrm{UV} / \mathrm{Vis}$ controlled until complete disappearance of the starting reagents if not additionally specified.
Electronic absorption (UV-Vis) spectra were recorded on a ThermoSpectronic Helios- $\alpha$ spectrophotometer using quartz cells $(0.5 \times 1 \mathrm{~cm})$. MALDI-TOF mass spectra were taken on a VISION-2000 mass spectrometer with 2-[(2E)-3-(4-tert-butylphenyl)-2-methylprop2-enylidene]-malonitrile (DCTB) as the matrix. High resolution MALDI mass spectra were registered on a Bruker ULTRAFLEX II TOF/TOF instrument with DCTB as the matrix. ${ }^{1} \mathrm{H}$ and ${ }^{13} \mathrm{C}$ NMR spectra were recorded on a Bruker "Avance 400" spectrometer (400.13 and $100.61 \mathrm{MHz}$ respectively) at $20^{\circ} \mathrm{C}$ (if not additionally specified). Chemical shifts are given in ppm relative to $\mathrm{SiMe}_{4}$.

Electrochemical measurements were carried out using IPCPro (Econix, Moscow, Russia) and EmStat (Palm Instrument BV, Utrecht, the Netherlands) potentiostats. Cyclic voltammetry (CVA) and square-wave voltammetry (SWVA) were performed in a conventional three electrode cell using Pt-disk ( $2.0 \mathrm{~mm}$ in diameter) working and Pt-foil counter electrodes. A calomel reference electrode ( $\mathrm{SCE}, 3 \mathrm{M} \mathrm{NaCl}$ ) was connected to the solution through a salt-bridge and a Luggin capillary, whose tip was placed close to the working electrode. The junction potentials were corrected by ferrocenium ${ }^{+} /$ ferrocene $\left(\mathrm{Fc}^{+} / \mathrm{Fc}\right)$ couple each time after a series of measurements $\left(E_{1 / 2}\left(\mathrm{FeFc}_{2}\right)=0.592 \mathrm{~V}\right)$. Freshly distilled dichloromethane (purium, Reachim Russia) and o-dichlorobenzene (DCB, 99\% SigmaAldrich, HPLC-grade) freshly passed through an $\mathrm{Al}_{2} \mathrm{O}_{3}$ layer were used as solvents, and $0.15 \mathrm{M}$ solution of $\mathrm{Bu}_{4} \mathrm{NBF}_{4}$ (Sigma-Aldrich, dried under vacuum at $+80^{\circ} \mathrm{C}$ ) in $o$-dichlorobenzene containing $(2 \div 10) \cdot 10^{-4} \mathrm{M}$ of sample was bubbled with argon for $20 \mathrm{~min}$ before measurements. Blank voltammograms were recorded in the same background solution.

AFM studies were carried out by means of a Solver-P47H (NT-MDT) microscope. Tapping mode and a high accuracy composite silicon/polysilicon HA_NC probe for non-contact AFM were applied to obtain images. Menzel-Gläser cover slips $(18 \times 18$ $\mathrm{mm}$ ) were employed as the substrate. The rounding-off radius of the probe was less than $10 \mathrm{~nm}$.

2-Iodo-4,5,6,7-tetrahydrobenzo[ $b]$ thiophene-3-carbonitrile was synthesized according to the published procedures. ${ }^{[6,7]}$ 
4,5,6,7-Tetrahydrobenzo[b]thiophene-2,3-dicarbonitrile (1)<smiles>N#Cc1sc2c(c1C#N)CCCC2</smiles>

1

A mixture of 2-iodo-4,5,6,7-tetrahydrobenzo[b]thiophene-3carbonitrile $(2.400 \mathrm{~g}, 8.3 \mathrm{mmol})$ and $\mathrm{CuCN}(1.850 \mathrm{~g}, 0.020 \mathrm{~mol})$ were refluxed in DMF $(40 \mathrm{ml})$ for $10 \mathrm{~h}$ (TLC-control: $\mathrm{Al}_{2} \mathrm{O}_{3}, \mathrm{C}_{6} \mathrm{H}_{6}$ : $n$-hexane $(1: 1 \mathrm{~V} / \mathrm{V}))$. The reaction mixture was cooled to room temperature and water was added. The product was collected by extraction with dichloromethane. The organic layer was dried with $\mathrm{CaCl}_{2}$. The solvent was evaporated and the resulting solid was purified twice by column chromatography $\left(\mathrm{Al}_{2} \mathrm{O}_{3}, \mathrm{CHCl}_{3}\right)$. This yielded 1 as a pale yellow solid $(1.020 \mathrm{~g}, 64 \%) . \mathrm{mp} 82.6^{\circ} \mathrm{C}$ (lit. $\left.{ }^{[6]} 82-83^{\circ} \mathrm{C}\right), R_{\mathrm{f}}=0.4$ $\left(\mathrm{Al}_{2} \mathrm{O}_{3}, \mathrm{C}_{6} \mathrm{H}_{6}: n\right.$ - hexane $\left.(1: 1 \mathrm{~V} / \mathrm{V})\right),{ }^{1} \mathrm{H}$ NMR $\left(400 \mathrm{MHz}, \mathrm{CDCl}_{3}\right) \delta_{\mathrm{H}}$ ppm: $1.85-1.93\left(\mathrm{~m}, 4 \mathrm{H}, \beta_{1,2}-\mathrm{CH}_{2}\right), 2.73\left(\mathrm{t}, J=5.7 \mathrm{~Hz}, 2 \mathrm{H}, \alpha_{1}-\mathrm{CH}_{2}\right)$, $2.81\left(\mathrm{t}, J=5.7 \mathrm{~Hz}, 2 \mathrm{H}, \alpha_{2}-\mathrm{CH}_{2}\right) \cdot{ }^{13} \mathrm{C} \mathrm{NMR}\left(100 \mathrm{MHz}, \mathrm{CDCl}_{3}\right) \delta_{\mathrm{c}} \mathrm{ppm}$ : 21.38, $22.39\left(\beta_{1,2}-\mathrm{CH}_{2}\right), 24.36,25.22\left(\alpha_{1,2}-\mathrm{CH}_{2}\right), 111.60$ and 111.93 (CN), 113.70 (C2), 119.47 (C3), 138.39 (C4), 145.71 (C5).

2,3,8,9,14,15,20,21-Octakis [4', ', ', 6', 7'-tetrahydrobenzo]tetra-2,3-thiophenophorphyrazine magnesium (2).

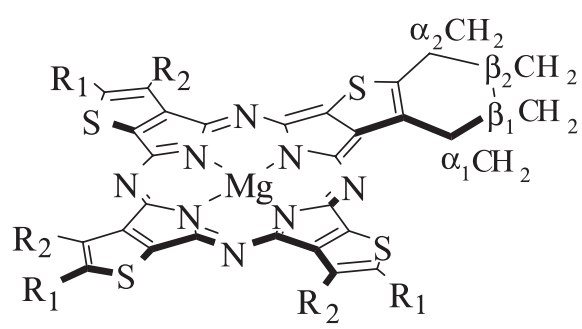

2

$$
\mathrm{R}_{1}, \mathrm{R}_{2}=-\left[\mathrm{CH}_{2}\right]_{4^{-}}
$$

A mixture of $1(0.200 \mathrm{~g}, 1.064 \mathrm{mmol}), \mathrm{Mg}(\mathrm{OAc})_{2} \cdot 4 \mathrm{H}_{2} \mathrm{O}$ $(0.143 \mathrm{~g}, 0.668 \mathrm{mmol})$ and lithium methoxide $(0.019 \mathrm{~g}, 0.500 \mathrm{mmol})$ were refluxed in $n$-octanol $(3.5 \mathrm{ml})$ for $8 \mathrm{~h}$ (TLC-control: $\mathrm{Al}_{2} \mathrm{O}_{3}$, $\mathrm{C}_{6} \mathrm{H}_{6}$ ). The reaction mixture was cooled to room temperature and a mixture $\mathrm{MeOH}: \mathrm{H}_{2} \mathrm{O}(10: 1 \mathrm{~V} / \mathrm{V})$ was added. A dark green precipitate was filtered and washed with water and $\mathrm{MeOH}$. This yielded 2 (0.093 g, 45\%). UV-Vis (THF) $\lambda_{\text {max }} \mathrm{nm}$ (lge): 663 (4.49), 639 (3.98), 603 (3.77), 369 (4.35). ${ }^{1} \mathrm{H}$ NMR (400 MHz, CDCl 3 : $\mathrm{MeOH} 100: 1$ $\mathrm{V} / \mathrm{V}) \delta_{\mathrm{H}} \mathrm{ppm}: 1.77\left(\mathrm{~m}, 16 \mathrm{H}, \beta_{1,2}-\mathrm{CH}_{2}\right), 2.65-2.70\left(\mathrm{~m}, 16 \mathrm{H}, \alpha_{1,2}-\mathrm{CH}_{2}\right)$. MS-MALDI-TOF $m / z: 776\left([\mathrm{M}]^{+}, 100 \%\right)$.

2,3,8,9,14,15,20,21-Octakis [4', 5', 6', $7^{\prime}$-tetrahydrobenzo]tetra-2,3-thiophenophorphyrazine zinc (3).

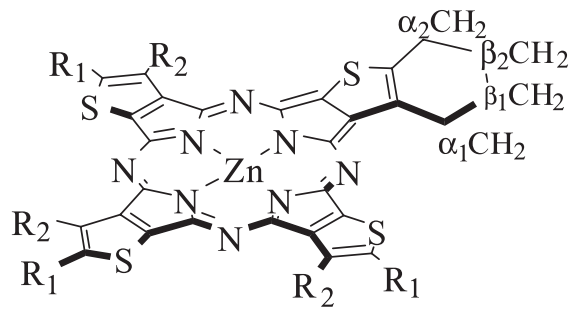

3

$$
\mathrm{R}_{1}, \mathrm{R}_{2}=-\left[\mathrm{CH}_{2}\right]_{4^{-}}
$$

A mixture of $1(0.070 \mathrm{~g}, 0.370 \mathrm{mmol}), \mathrm{Zn}(\mathrm{OAc})_{2} \cdot 4 \mathrm{H}_{2} \mathrm{O}$ $(0.047 \mathrm{~g}, 0.185 \mathrm{mmol})$ and lithium methoxide $(0.007 \mathrm{~g}, 0.185$ $\mathrm{mmol})$ were refluxed in $\mathrm{n}$-octanol $(1.5 \mathrm{ml})$ for $5 \mathrm{~h}$ (TLC-control:
$\left.\mathrm{Al}_{2} \mathrm{O}_{3}, \mathrm{C}_{6} \mathrm{H}_{6}\right)$. The reaction mixture was cooled to room temperature and a mixture $\mathrm{MeOH}: \mathrm{H}_{2} \mathrm{O}(10: 1 \mathrm{~V} / \mathrm{V})$ was added. A dark green precipitate was filtered and washed with water and $\mathrm{MeOH}$. This yielded 3 (0.061 g, 80\%). UV-Vis (THF) $\lambda_{\max } \mathrm{nm}(\lg \varepsilon)$ : 665 (4.6), 603 (3.9), 367 (4.4). ${ }^{1} \mathrm{H}$ NMR (400 MHz, Py-d $)_{5} \delta_{\text {н }}$ ppm: 2.02 (m, $\left.8 \mathrm{H}, \beta_{2}-\mathrm{CH}_{2}\right), 2.08\left(\mathrm{~m}, 8 \mathrm{H}, \beta_{1}-\mathrm{CH}_{2}\right), 3.11-3.16\left(\mathrm{~m}, 8 \mathrm{H}, \alpha_{2}-\mathrm{CH}_{2}\right)$, 3.84-3.98 (m, 8H, $\left.\alpha_{1}-\mathrm{CH}_{2}\right)$. HRMS-MALDI-TOF/TOF $\mathrm{m} / \mathrm{z}$ : [M] ${ }^{+}$ calculated for $\mathrm{C}_{40} \mathrm{H}_{34} \mathrm{~N}_{8} \mathrm{~S}$ Zn: 818.4057; found: 818.4082 .

$2,3,8,9,14,15,20,21$-Octakis [4', 5', 6', $7^{\prime}$-tetrahydrobenzo]25H,27H-tetra-2,3-thiophenophorphyrazine (4).

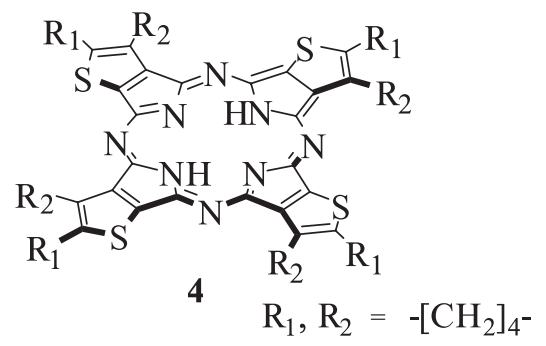

a) Approach with concentrated sulfuric acid. The magnesium complex 2 (0.011 g, $0.014 \mathrm{mmol})$ was dissolved in concentrated sulfuric acid $(3 \mathrm{ml})$. This solution was poured into the ice. At the same time the green precipitate was formed. This precipitate was filtered and washed with water and $\mathrm{MeOH}$ to give $4(0.004 \mathrm{~g}, 38 \%)$. UV-Vis (THF) $\lambda_{\max } \mathrm{nm}(\lg \varepsilon): 699$ (4.60), 655 (4.54), 352 (4.55). HRMS-MALDI-TOF/TOF: $\mathrm{m} / z[\mathrm{M}]^{+} \cdot$ calculated for $\mathrm{C}_{40} \mathrm{H}_{34} \mathrm{~N}_{8} \mathrm{~S}_{4}$ : $754.2912[\mathrm{M}]^{+}$; found: 754.3190 .

b) Approach with concentrated trifluoroacetic acid. The magnesium complex 2 (0.011 g, $0.014 \mathrm{mmol})$ was dissolved in concentrated trifluoroacetic acid $(3 \mathrm{ml})$. This solution was poured into the ice. At the same time the green precipitate was formed. This precipitate was filtered and washed with water and $\mathrm{MeOH}$ to give $4(0.005 \mathrm{~g}, 48 \%)$. The characteristics were identical with those obtained by method $(a)$.

c) Approach with pyridine hydrochloride. A mixture of $\mathbf{3}$ $(0.030 \mathrm{~g}, 0.0370 \mathrm{mmol})$ and pyridine hydrochloride $(0.012 \mathrm{~g}, 0.10$ $\mathrm{mmol})$ were refluxed in pyridine $(600 \mu \mathrm{l})$ for $3 \mathrm{~h}$. The reaction mixture was cooled to room temperature and a mixture $\mathrm{MeOH}: \mathrm{H}_{2} \mathrm{O}$ $(10: 1 \mathrm{~V} / \mathrm{V})$ was added. A dark green precipitate was filtered and washed with water and $\mathrm{MeOH}$. This yielded $4(0.026 \mathrm{~g}, 93 \%)$. The characteristics were identical with those obtained by method $(a)$.

2,3,8,9,14,15,20,21-Octakis [4',5',6',7'-tetrahydrobenzo]tetra-2,3-thiophenophorphyrazinatolutetium acetate (5).

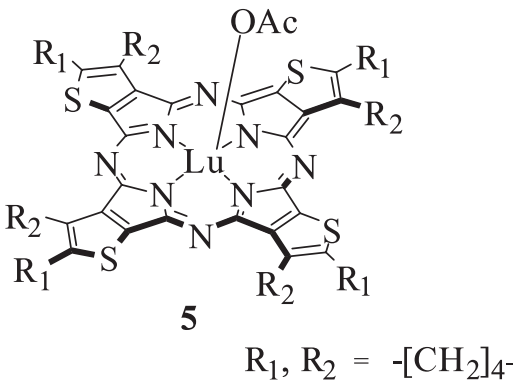

A mixture of 4 (12 mg, $0.016 \mathrm{mmol}), \mathrm{Lu}(\mathrm{OAc})_{3} \cdot 4 \mathrm{H}_{2} \mathrm{O}(3 \mathrm{mg}$, $0.007 \mathrm{mmol})$ and lithium methoxide $(0.004 \mathrm{~g}, 0.105 \mathrm{mmol})$ were heated in the mixture TCB: $\mathrm{C}_{16} \mathrm{H}_{33} \mathrm{OH}\left(1: 1 \mathrm{~V} / \mathrm{V} ; \mathrm{V}_{\text {total }}=300 \mu \mathrm{l}\right)$ at the temperature range: $190-230^{\circ} \mathrm{C}$ for $2.5 \mathrm{~h}$ (TLC-control: $\mathrm{Al}_{2} \mathrm{O}_{3}$, $\left.\mathrm{C}_{6} \mathrm{H}_{6}\right)$. The reaction mixture was cooled to room temperature and a mixture $\mathrm{MeOH}: \mathrm{H}_{2} \mathrm{O}(5: 1 \mathrm{~V} / \mathrm{V})$ was added. A dark green precipitate was filtered and washed with water and $\mathrm{MeOH}$. The compound 5 was separated using preparative TLC $\left(\mathrm{Al}_{2} \mathrm{O}_{3}, \mathrm{C}_{6} \mathrm{H}_{6}\right)$. This yielded $\mathbf{5}$ $(0.010 \mathrm{~g}, 63 \%) . R_{\mathrm{f}}=0.3\left(\mathrm{Al}_{2} \mathrm{O}_{3}, \mathrm{C}_{6} \mathrm{H}_{6}\right) . \mathrm{UV}-\mathrm{Vis}(\mathrm{THF}) \lambda_{\max } \mathrm{nm}(\lg \varepsilon)$ : 
664 (4.53), 604 (3.98), 362 (4.43). HRMS-MALDI-TOF/TOF: $\mathrm{m} / \mathrm{z}[\mathrm{M}-\mathrm{OAc}-\mathrm{H}]^{+}$calculated for $\mathrm{C}_{40} \mathrm{H}_{31} \mathrm{LuN}_{8} \mathrm{~S}_{4}$ : 926.0962; found: 926.0688 .

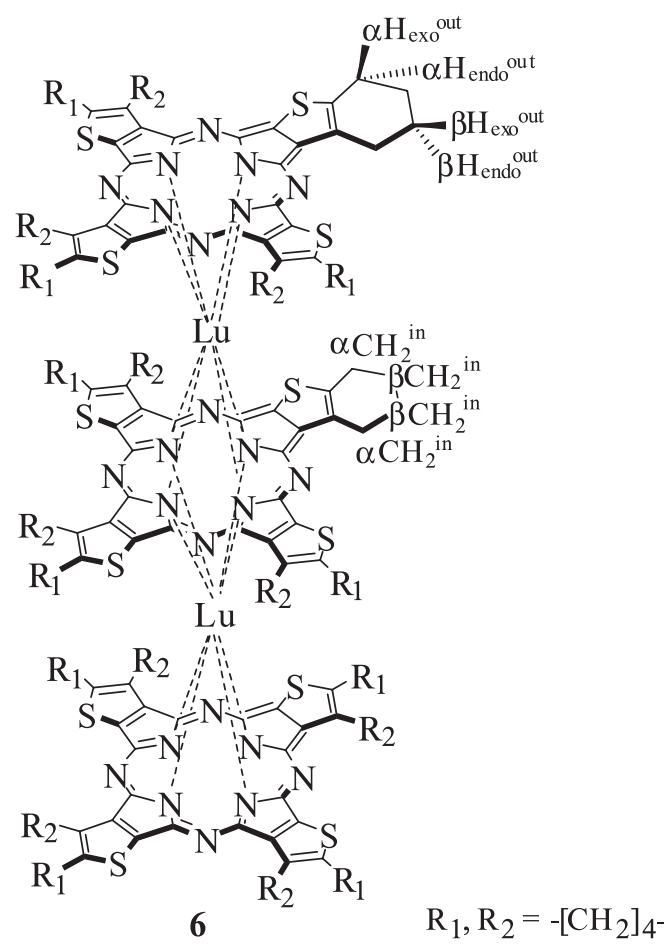

Tris $\left[2,3,8,9,14,15,20,21\right.$-octakis $\left[4^{\prime}, 5^{\prime}, 6^{\prime}, 7^{\prime}\right.$-tetrahydrobenzo]tetra-2,3-thiophenophorphyrazine] dilutetium (6) was separated using preparative TLC $\left(\mathrm{Al}_{2} \mathrm{O}_{3}, \mathrm{C}_{6} \mathrm{H}_{6}\right)$. This yielded $\mathbf{6}$ $(0.005 \mathrm{~g}, 36 \%) . R_{\mathrm{f}}=0.8\left(\mathrm{Al}_{2} \mathrm{O}_{3}, \mathrm{C}_{6} \mathrm{H}_{6}\right)$. UV-Vis (THF) $\lambda_{\text {max }} \mathrm{nm}(\lg \varepsilon)$ : 698 (3.85), 656 (4.59), 551 (3.67), 371 (4.45), 310 (4.37). ${ }^{1} \mathrm{H}$ NMR $\left(400 \mathrm{MHz}, \mathrm{CDCl}_{3}\right) \delta_{\mathrm{H}} \mathrm{ppm}: 1.96\left(\mathrm{~m}, 16 \mathrm{H}, \beta-\mathrm{H}_{\text {ехо }}{ }^{\text {out }}\right), 2.09(\mathrm{~m}, 16 \mathrm{H}$, $\left.\beta-\mathrm{H}_{\text {endo }}{ }^{\text {out }}\right), 2.32\left(\mathrm{~m}, 16 \mathrm{H}, \beta-\mathrm{H}^{\text {in }}\right), 2.60\left(\mathrm{~m}, 16 \mathrm{H}, \alpha-\mathrm{H}_{\text {exo }}{ }^{\text {out }}\right), 2.84(\mathrm{~m}$, $\left.16 \mathrm{H}, \alpha-\mathrm{H}_{\text {endo }}{ }^{\text {out }}\right), 3.55\left(\mathrm{~m}, 16 \mathrm{H}, \alpha-\mathrm{H}^{\text {in }}\right)$. HRMS (MALDI-TOF/TOF) $m / z:[\mathrm{M}]^{+} \cdot$ calculated for $\mathrm{C}_{120} \mathrm{H}_{96} \mathrm{Lu}_{2} \mathrm{~N}_{24} \mathrm{~S}_{12}: 2608.9210$; found: 2608.8909 .

\section{Results and Discussion}

4,5,6,7-Tetrahydrobenzo[b]thiophene-2,3-dicarbonitrile was chosen as the starting compound. This dinitrile was obtained by a standard synthetic route. ${ }^{[6,7]}$ Replacement of 1,1,3,3-tetramethylurea ${ }^{[6]}$ by DMF at the stage of cyanation allowed for an increase in yield from 47 to $64 \%$. According to the literature data, ${ }^{[6]}$ tetrathieno[2,3-b]porphyrazines can exist as a mixture of four possible isomers (excluding the isomers of cyclohexene moieties), $C_{4 \mathrm{~h}}, C_{\mathrm{S}}, D_{2 \mathrm{~h}}$ and $C_{2 \mathrm{v}}$, which cannot be separated. Four similar randomers also occur for 1,2-naphthalocyanines. ${ }^{[8,9]}$

The porphyrazine complexes were synthesised from the dinitrile $\mathbf{1}$ and acetates of corresponding metals in boiling $n$-octanol upon addition of lithium methoxide base (Scheme 1). Magnesium and zinc ions were chosen for the subsequent formation of ligands. ${ }^{[10]}$ Formation of porphyrazines was not observed under mild conditions in a boiling isoamilic alcohol. Metal-free porphyrazine was obtained by the method discribed for phthalo- and naphthalocyanine ligands, ${ }^{[10 c, 11]}$ which involved treatment of magnesium complex $\mathbf{2}$ with strong concentrated acids (Scheme 1). However, partial destruction of thiophene moieties under polymerisation in concentrated acid led to a low yield of target compound.
Treatment of magnesium complex 2 with a weaker acetic acid did not yield 4. Demetallation was done under mild conditions, as recently reported for zinc phthalocyanines. This approach includes a reaction between zinc complex and pyridine hydrochloride in boiling pyridine and is based on formation of a ternary pyridine- $\mathrm{Zn}-\mathrm{Pc}$ complex with square pyrimidal zinc coordination. ${ }^{[10 a]}$ Present work is the first successful example of the synthesis of porphyrazine compounds by such route.

Phthalocyanine and porphyrazine complexes of rare earth elements (REE) find a large range of applications in optics and electronics. ${ }^{[12]}$ In light of that, we have chosen to synthesize a lutetium complex of $\mathbf{4}$ as our first example. Tetrathieno[2,3-b]porphyrazine lutetium $\mathbf{5}$ was obtained by a reaction of ligand $\mathbf{4}$, lutetium acetate and lithium methoxide in the mixture of cetyl alcohol and TCB (1:1 volume ratio) (Scheme 1).

Substituted triple-decker lutetium porphyrazine 6 was separated as a by-product in the synthesis of $\mathbf{5}$. Noteworthy, this is the first example of sandwich-type porphyrazine with annelated heterocyclic ring. Formation of the doubledecker complex 7 was confirmed by MALDI TOF mass spectrometry, but all attempts to isolate the product were unsuccessful. Perhaps, this is due to the low stability of $\pi$-radical thienoporphyrazine structures. Even the standard synthetic route ( $\mathrm{Lu}$ acetylacetonate; lithium methoxide; $190^{\circ} \mathrm{C} ; n$-octanol $)^{[13]}$ did not yield double-decker complex. Novel porphyrazines 2-6 were characterized by high resolution MALDI-TOF mass spectrometry, UV-Vis and ${ }^{~} \mathrm{H}$ NMR spectroscopy.

UV-Vis spectra of the obtained porphyrazines are very instructive. Metal-free $\mathbf{4}$ exhibits $Q$-band splitting (Figure 1a), that can be attributed to the non-degenerated LUMO orbital. ${ }^{[14]}$ In contrast, $Q$-bands in complexes 2, 3, 5 were not split (Figure 1 and Table 1). This result is in accord with the literature data ${ }^{[15]}$ and DFT calculation ${ }^{[14]}$ for porphyrazines. The absence of $Q$-band splitting and the values of full width at half maximum (FWHM) for porphyrazine complexes in THF (Table 1.) allow to conclude that $C_{4 \mathrm{~h}}$ and $C_{2 \mathrm{~V}}$ randomers ${ }^{[9]}$ predominate in the mixture. A weak intensity broad band, which is characteristic for phthalocyanines and porphyrazines that containing chalcogenide atoms, was observed in the range of $400-450 \mathrm{~nm}$. This band refers to the charge transfer from thiophene cycles to porphyrazine core. ${ }^{[3 a]}$ Compared to unsubstituted thieno[2,3-b]porphyrazine, ${ }^{[6]}$ $Q$-bands for tetrahydrobenzo substituted complexes are bathochromically shifted. This phenomenon can be explained by the donor effect of substituents. Nature of the central metal in porphyrazine complexes did not influence the $Q$-band position (Figure 1), as was also the case for monophthalo- and naphthalocyanines. ${ }^{[11]} Q$-band of the metal-free compound $\mathbf{4}$ had a bathochromic shift with respect to $Q$-bands of complexes $\mathbf{2 , 3}$ and $\mathbf{5}$. The triple-decker complex $\mathbf{6}$ exhibits $Q$-band splitting and a hypsochromic shift of the main absorption maximum as compared to those of monoporphyrazines. Similar features have been previously reported for triple-decker phthalocyanine complexes ${ }^{[16,17]}$ and are due to the interaction of the inner and external deck. $^{[13]}$

The spectra of porphyrazines $2-5$ in a non-coordinating solvent $\left(\mathrm{C}_{6} \mathrm{H}_{6}\right)$ exhibit aggregation behaviour that is 


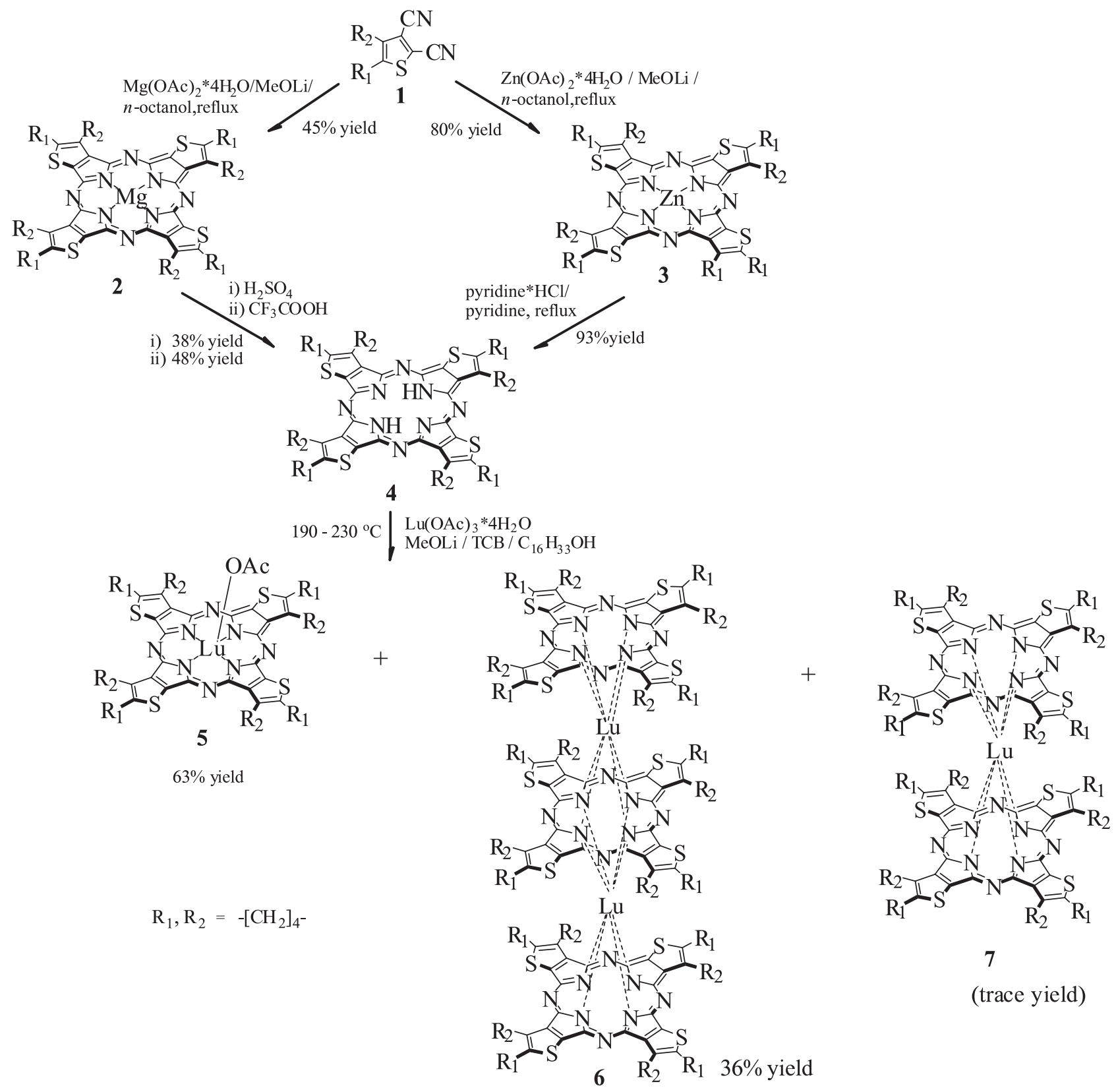

Scheme 1. Synthesis of thienoporphyrazine complexes 2-7 (the structures of complexes are shown for one isomer).

manifested in broadening of $Q$-bands and decreasing of the $Q$-band: $B$-band intensity ratio $I / I_{\max }$ (Table 1 ). Due to the steric effect of external decks the aggregation was minimal in the case of the triple-decker compound $\mathbf{6}$.

The aggregation effect was stronger in solid films of 6. Films possessed an "island-type", large-grain structure (Figure 2). Grain size depended on the coordination effect of the solvent. In the case of $\mathrm{C}_{6} \mathrm{H}_{6}$ the grain size was 45 $\mathrm{nm}$ in height and $200 \mathrm{~nm}$ in width. For highly-coordinating THF, grain size was $7 \mathrm{~nm}$ in height and from 60 to $80 \mathrm{~nm}$ in width.

Electrochemical behaviour of complex 3 in $o$-DCB was investigated (Figure 3). The square-wave voltammogram (SWVA) exhibited three reduction potentials at -0.915 , -1.295 and $-1.735 \mathrm{~V}$ and two oxidation potentials at +0.835 and $+1.520 \mathrm{~V}$. In cyclic voltammogram (CVA), only highly-reversible redox processes $\operatorname{Red}_{1}, \operatorname{Red}_{2}$ and $\mathrm{Ox}_{1}$ were observed, which is likely due to the lower sensitivity of the method. Under the potential scanning until $1.6 \mathrm{~V}$ and higher, poor reversibility of the $\mathrm{Ox}_{2}$ process resulted in a decrease of intensity and a shift of the reverse peak of $\mathrm{Ox}_{1}$.

Investigation of nonlinear optical properties was carried out using a well known Z-scan technique. ${ }^{[18]}$ The scheme of the experiment is presented in Figure 4.

In our study we used a Nd:YAG laser operated at the $\mathrm{TEM}_{00}$ mode with the pulse duration of $\tau_{p}=350 \mathrm{ps}$ (halfwidth at $e^{-1}$ intensity) at the repetition rate of $5 \mathrm{~Hz}$. To obtain the second harmonic at $532 \mathrm{~nm}$ we used an ADP-crystal. The beam was tightly focused and the beam radius (halfwidth at $e^{-2}$ intensity) was $\omega_{0}=30 \mu$ at the focus. The energy of the pulse was $E_{0}=38 \mu \mathrm{J}$. Measurements with closed aperture help to reveal the characteristics of the nonlinear refraction. The measurements with open aperture reveal the characteristics of the non-linear absorption. 

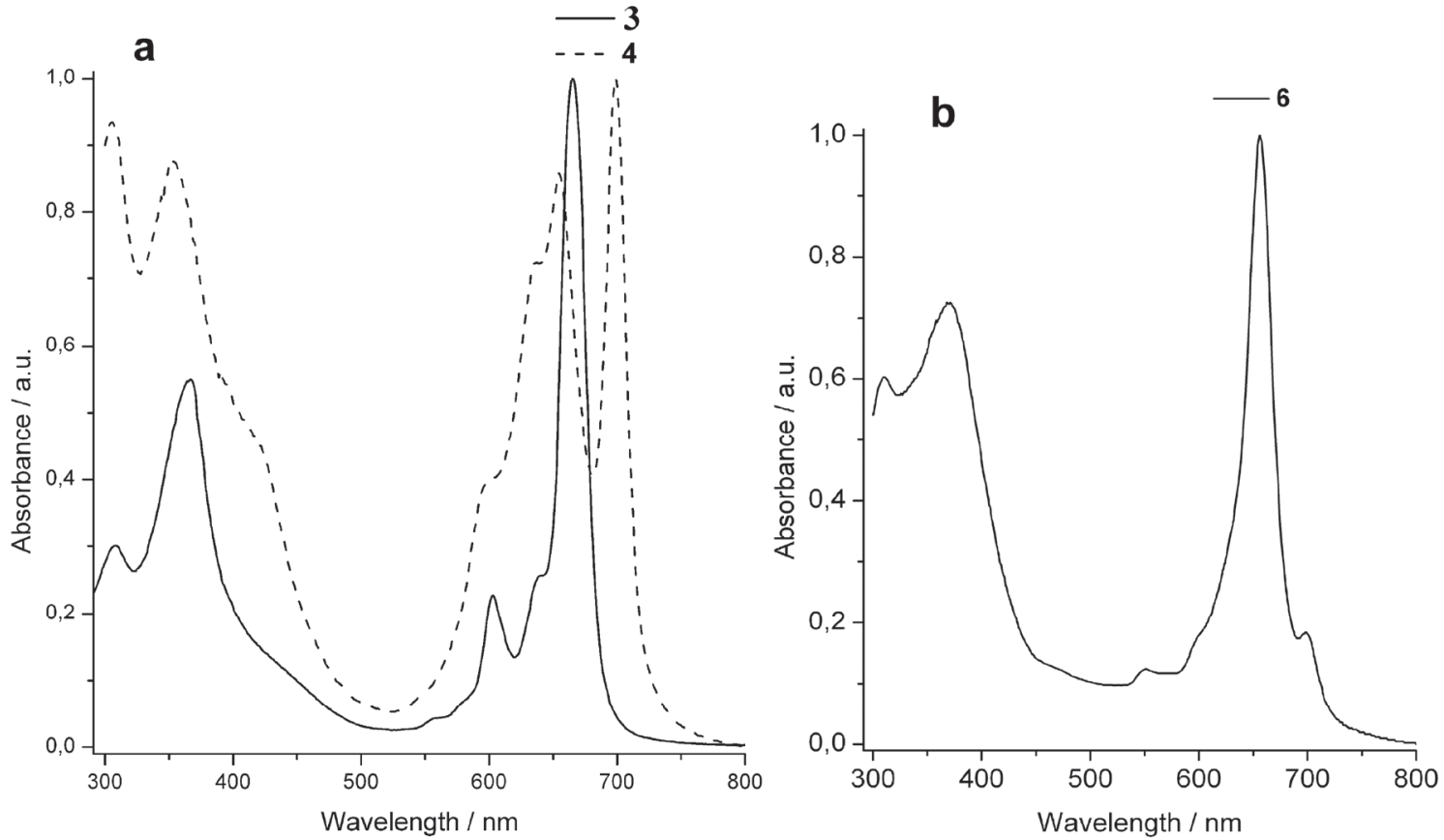

Figure 1. UV-Vis spectra of thienoporphyrazines 3, 4 and 6 in THF.
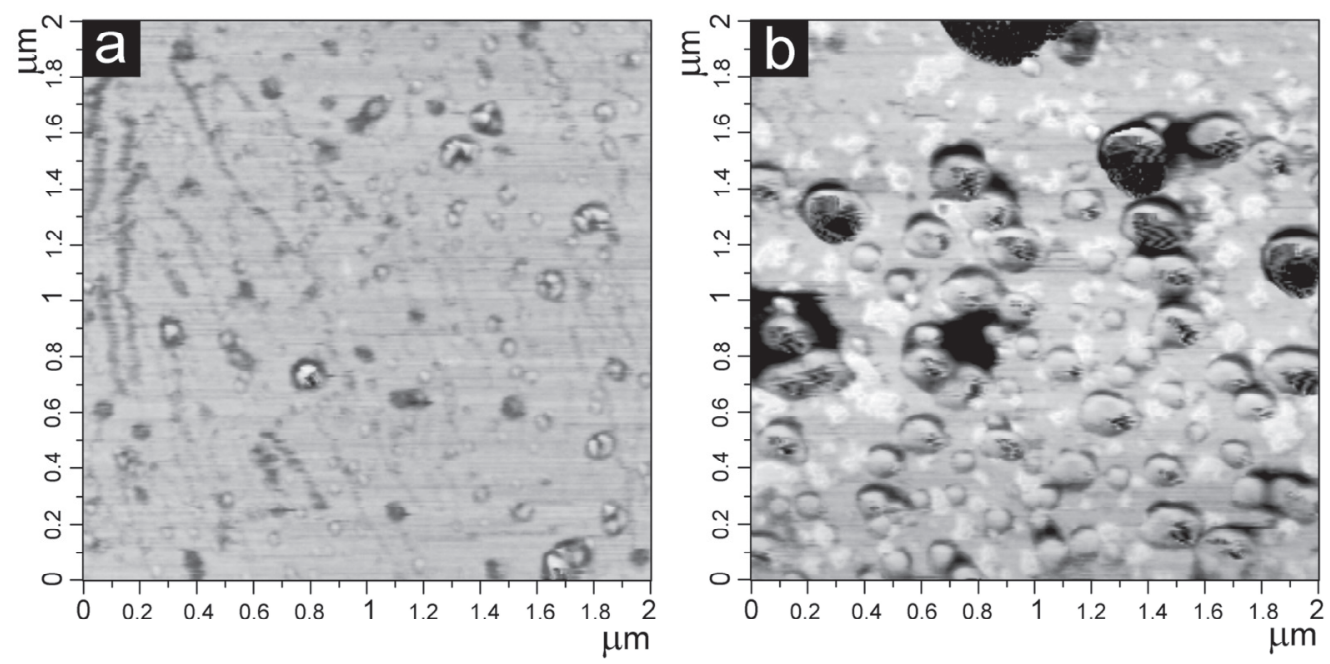

Figure 2. AFM phase contrast images of thin films of compound $\mathbf{6}$ deposited from a THF solution (a) and from a $\mathrm{C}_{6} \mathrm{H}_{6}$ solution $(\mathrm{b})\left(\mathrm{C}=10^{-6}\right.$ M).

Table 1. UV-Vis spectral data for compounds 2-6.

\begin{tabular}{|c|c|c|c|c|}
\hline Compound & $\lambda\left(I / I_{\max }\right), \mathrm{nm}$ in THF & $\lambda\left(I / I_{\max }\right), \mathrm{nm}$ in $\mathrm{C}_{6} \mathrm{H}_{6}$ & $\begin{array}{c}\text { Full Width at Half } \\
\text { Maximum (FWHM) for } \\
Q \text {-band (nm) in THF }\end{array}$ & $\begin{array}{l}\text { Full Width at Half Maximum } \\
\text { (FWHM) for } \\
Q \text {-band (nm) in } \mathrm{C}_{6} \mathrm{H}_{6}\end{array}$ \\
\hline 2 & $\begin{array}{l}663(1.00) ; 639(0.31) ; \\
603(0.19) ; 369(0.77)\end{array}$ & $\begin{array}{c}668(0.83) ; 611(0.24) ; 373 \\
(1.00) ; 306(0.59)\end{array}$ & $20(663)$ & 27 (668) \\
\hline 3 & $\begin{array}{c}665(1.00) ; 603(0.23) ; \\
367(0.55)\end{array}$ & $\begin{array}{c}672(1.00) ; 641(0.42) ; 619 \\
(0.41) ; 363(0.94) ; 310(0.57)\end{array}$ & $21(665)$ & $26(672)$ \\
\hline 4 & $\begin{array}{c}699(1.00) ; 655(0.86) \\
352(0.88)\end{array}$ & $\begin{array}{c}700(0.92) ; 656(0.87) ; 638 \\
(0.80) ; 358(1.00) ; 312 \\
(0.78)\end{array}$ & 15 (699) & $16(700)$ \\
\hline 5 & $\begin{array}{c}664(1.00) ; 604(0.28) ; \\
362(0.79)\end{array}$ & $\begin{array}{c}667(0.97) ; 605(0.34) ; 363 \\
(1.00) ; 305(0.88)\end{array}$ & 20 (664) & $26(667)$ \\
\hline 6 & $\begin{array}{c}698(0.18) ; 656(1.00) ; \\
551(0.12) ; 371(0.72) ; \\
310(0.60)\end{array}$ & $\begin{array}{c}697(0.19) ; 655(1.00) ; 550 \\
(0.15) ; 371(0.81) ; 314 \\
(0.60)\end{array}$ & 19 (698) & $20(655)$ \\
\hline
\end{tabular}




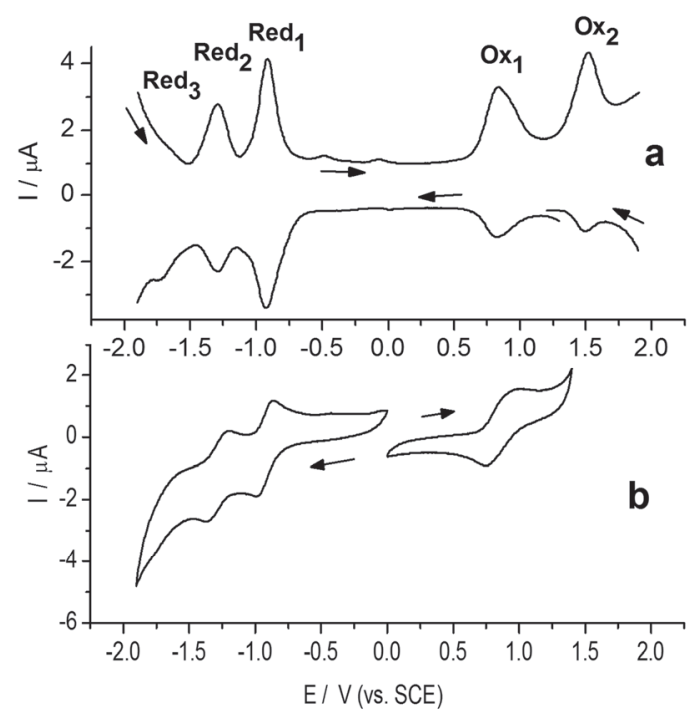

Figure 3. Square wave (a) and cyclic (b) voltammograms of $\mathbf{3}$ in $o$-DCB.

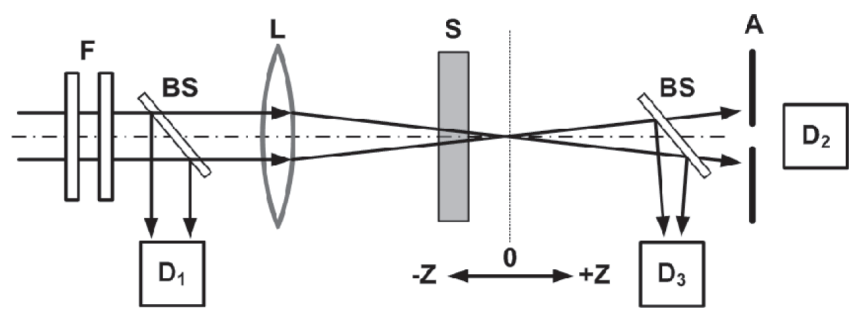

Figure 4. The Z-scan setup. F- filters, BS - beam splitter, $\mathrm{D}_{1}, \mathrm{D}_{2}$ and $\mathrm{D}_{3}$ are photodetectors, $\mathrm{A}$ - aperture, $\mathrm{S}$ - sample.

Table 2. NLO measurements data for compound 3.

\begin{tabular}{ccccc}
\hline Compound & $\operatorname{Re} \chi^{(3)}(\mathrm{esu})$ & $\operatorname{Im} \chi^{(3)}(\mathrm{esu})$ & $\lambda(\mathrm{nm})$ & $\mathrm{I}\left(\mathrm{GW} / \mathrm{cm}^{2}\right)$ \\
\hline $\mathbf{2 6}$ & $3.45 \cdot 10^{-14}$ & $11.5 \cdot 10^{-14}$ & 532 & 2.5 \\
\hline
\end{tabular}

Here we present the best result, which was reached for $\mathrm{Zn}$ complex. In Table 2 there are the real part of nonlinear optical susceptibility, corresponded to nonlinear refraction, and the imaginary part of nonlinear optical susceptibility, corresponded to nonlinear absorption. This compound posseses the negative nonlinearity (Figure 5), which increases under the increase in the concentration of target compound in solution. Noteworthy, that metal-free and triple-decker compounds did not show remarkable nonlinearity for the similar concentrations.

As one can see from the open-aperture z-scan (Figure 5a) the sample shows reverse saturable absorption. To interpret the experimental data it is convenient to use the five-level model. The five-level model is represented with the Jablonski diagram which describes processes of excitation and relaxation in the molecule. In this model commonly only one-photon processes are considered. The scheme of the model is presented in Figure 6. The ground state is signed as $S_{0}$.

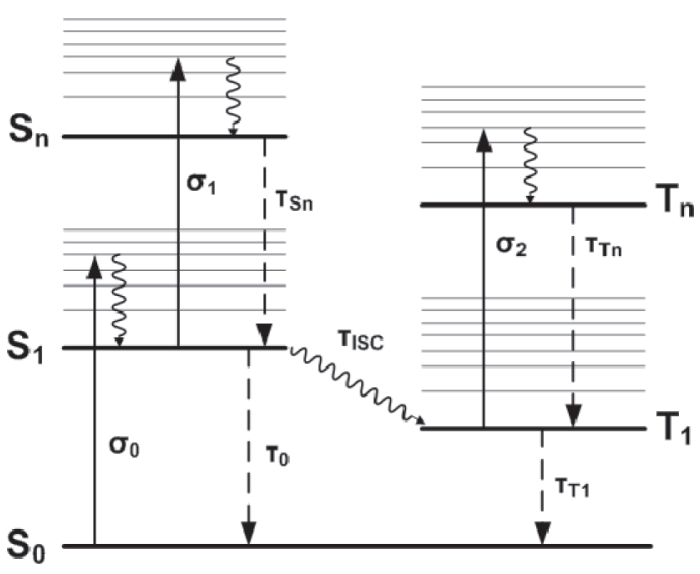

Figure 6. Jablonski diagram of excitation and relaxation processes in a molecule. ${ }^{[19]}$

Absorption of the photon at $532 \mathrm{~nm}$ leads to the transition of the electron to the vibronic sublevel of the first excited singlet state $S_{1}$. The lifetime of the vibronic sublevel is of subpicosecond range, so only the direct transition $\mathrm{S}_{0} \rightarrow \mathrm{S}_{1}$ can be considered. The electrons from $S_{1}$ can relax either to the ground state, with the lifetime $\tau_{0}$, or to the triplet state $T_{1}$ via intersystem crossing, with the
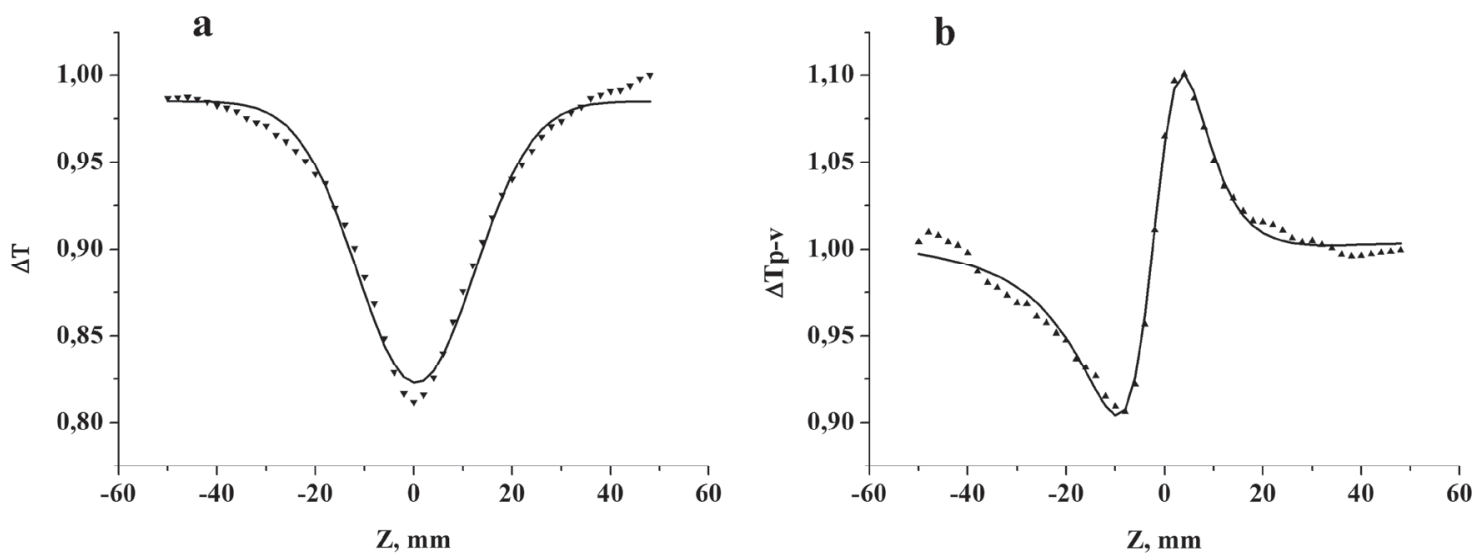

Figure 5. An open (a) and closed (b) aperture Z-scans measured for $\mathrm{Zn}$ complex in $\mathrm{C}_{6} \mathrm{H}_{6}\left(\mathrm{C}=6 \cdot 10^{-5} \mathrm{M}\right)$. 
lifetime $\tau_{I S C}$. Under the influence of the incident radiation excited electrons at states $S_{1}$ and $T_{1}$ will transit to upper excited states $S_{n}$ and $T_{n}$, respectively. The population dynamics of all mentioned states is described by system of rate equations:

$$
\begin{aligned}
& \frac{\mathrm{dN}_{0}}{\mathrm{dt}}=-\sigma_{0} \mathrm{~N}_{\mathrm{G}} \frac{\mathrm{I}}{\hbar \omega}+\frac{\mathrm{N}_{\mathrm{S} 1}}{\tau_{0}}+\frac{\mathrm{N}_{\mathrm{T} 1}}{\tau_{\mathrm{T} 1}} \\
& \frac{\mathrm{dN}_{\mathrm{S} 1}}{\mathrm{dt}}=\sigma_{0} \mathrm{~N}_{\mathrm{G}} \frac{\mathrm{I}}{\hbar \omega}-\sigma_{1} \mathrm{~N}_{\mathrm{S} 1} \frac{\mathrm{I}}{\hbar \omega}-\frac{\mathrm{N}_{\mathrm{S} 1}}{\tau_{0}}-\frac{\mathrm{N}_{\mathrm{S} 1}}{\tau_{\mathrm{ISC}}}+\frac{\mathrm{N}_{\mathrm{S} 2}}{\tau_{\mathrm{S} 2}} \\
& \frac{\mathrm{dN}_{\mathrm{S} 2}}{\mathrm{dt}}=\sigma_{1} \mathrm{~N}_{\mathrm{S} 1} \frac{\mathrm{I}}{\hbar \omega}-\frac{\mathrm{N}_{\mathrm{S} 2}}{\tau_{\mathrm{S} 2}} \\
& \frac{\mathrm{dN}_{\mathrm{T} 1}}{\mathrm{dt}}=-\sigma_{2} \mathrm{~N}_{\mathrm{T} 1} \frac{\mathrm{I}}{\hbar \omega}+\frac{\mathrm{N}_{\mathrm{S} 1}}{\tau_{\mathrm{ISC}}}+\frac{\mathrm{N}_{\mathrm{T} 2}}{\tau_{\mathrm{T} 2}}-\frac{\mathrm{N}_{\mathrm{T} 1}}{\tau_{\mathrm{T} 1}} \\
& \frac{\mathrm{dN}_{\mathrm{T} 2}}{\mathrm{dt}}=\sigma_{2} \mathrm{~N}_{\mathrm{T} 1} \frac{\mathrm{I}}{\hbar \omega}-\frac{\mathrm{N}_{\mathrm{T} 2}}{\tau_{\mathrm{T} 2}}
\end{aligned}
$$

where $N_{i}$ is the population of the $i$-th state, $\sigma_{0}$ is the ground state absorption cross-section, $\sigma_{1}$ is the first excited singlet state absorption cross-section, $\sigma_{2}$ is the first excited triplet state absorption cross-section, $\tau_{i}$ is the lifetime of the $i$-th state and $\tau_{I S C}$ is the intersystem crossing lifetime. The absorption in the sample is governed by the Beer's law:

$$
\frac{\mathrm{dI}}{\mathrm{dz}}=-\sigma_{0} \mathrm{IN}_{\mathrm{G}}-\sigma_{1} \mathrm{IN}_{\mathrm{S} 1}-\sigma_{2} \mathrm{IN}_{\mathrm{T} 1}
$$

where $z^{\prime}$ is the coordinate inside the sample. Where the first term describes the absorption of the ground state and the other two describe the absorption of excited singlet and triplet state, respectively. The transmittance of the pulse is determined by the formula

$$
\mathrm{T}(\mathrm{z})=\frac{\int_{-\infty}^{\infty} \mathrm{dt} \int_{0}^{\infty} \mathrm{I}_{\text {out }}(r, z, t) r d r}{\int_{-\infty}^{\infty} \mathrm{dt} \int_{0}^{\infty} \mathrm{I}_{\text {in }}(r, z, t) r d r}
$$

where $I_{\text {in }}$ and $I_{\text {out }}$ are the intensities of incident and transmitted pulses, respectively. Calculating transmittance for each z-position yields the z-scan curve.

The results we present in the Table 2 are calculated with the $\chi^{(3)}$ - formalism which doesn't describe full nature of the processes which take place during the illumination with intense laser pulse. It is necessary to use the fivelevel model. However, using of the model implies that lifetimes of the excited states are known. To calculate the values of $\sigma_{1}$ and $\sigma_{2}$ time-resolved measurements are needed. These measurements are very important to characterize the nonlinear optical properties and they are the subject of further investigation.

\section{Conclusions}

In conclusion, novel highly-soluble substituted porphyrazines were synthesised in high yields (45-80\%). The synthetic route to the thieno[2,3-b]porphyrazine complexes as a perspective building-blocks for sandwich-type porphyrazines was developed. Heterocyclic ring annelated sandwich-type porphyrazine complex was synthesised for the first time. Spectral properties and aggregation phenomena of target compounds were investigated by UV-Vis and AFM techniques. Electrochemical behaviour of the $\mathrm{Zn}$ complex was studied by CVA and SWWA and the presence of reversible redox processes was shown. The presence of induced absorption shows, that $\mathrm{Zn}$ complex can be used as an optical limiter.

Acknowledgements. The research was supported by the Russian Foundation for Basic Research (Grant No. 08-0300753), and the programme of the Presidium of the Russian Academy of Science "Development of a strategy of organic synthesis and creation of compounds with valuable and applied proprieties".

\section{References}

1. Linstead R.P., Noble E.G., Wright J.M. J. Chem. Soc. 1937, 911-921.

2. (a) Knawby D.M., Swager T.M. Chem. Mater. 1997, 9, 535-538. (b) Miyoshi Y., Fujimoto T., Yoshikawa H., Matsushita M.M., Awaga K., Yamada T., Ito H. Org. Electron. 2011, 12, 239-243. (c) Du C., Guo Y., Liu Y., Qiu W., Zhang H., Gao X., Liu Y., Qi T., Lu K., Yu G. Chem. Mater. 2008, 20, 4188-4190.

3. (a) Taraymovich E.S., Korzhenevskii A.B., Mitasova Y.V., Kumeev R.S., Koifman O.I., Stuzhin P.A. J. Porphyrins Phthalocyanines 2011, 15, 54-65. (b) Cook M.J., Jafari-Fini A Tetrahedron 2000, 56, 4085-4094.

4. Brown S.B., Brown E.A., Walker I. Lancet Oncol. 2004, 5, 497-508.

5. (a) Luo Q., Liu Y., Tian H., Photochromic DithienylethenePhthalocyanines and Their Analogs. In: Functional Phthalocyanine Molecular Materials (Jiang, J., Ed). Berlin Heidelberg: Springer-Verlag: Berlin, 2010; Vol. 135, 89-103; (b) de la Torre G., Claessens C. G., Torres T. Chem. Commun. (Cambridge, U. K.) 2007, 2000-2015.

6. Christie R.M., Freer B.G. Dyes Pigm. 1997, 33, 107-118.

7. Gewald K., Schinke E., Bottcher H. Chem. Ber. 1966, 99, 94100.

8. Hanack M., Renz G., Strähle J., Schmid S. Chem. Ber. 1988 , 121, 1479-1486.

9. Negrimovskii V.M., Bouvet M., Luk'yanets E.A., Simon J. $J$. Porphyrins Phthalocyanines 2000, 4, 248-255.

10. (a) Alzeer J., Roth P.J.C., Luedtke N.W. Chem. Commun. (Cambridge, U. K.) 2009, 1970-1971. (b) Dubinina T.V., Trashin S.A., Borisova N.E., Boginskaya I.A., Tomilova L.G., Zefirov N.S. Dyes Pigm. 2012, 93, 1471-1480. (c) Dubinina T.V., Ivanov A.V., Borisova N.E., Trashin S.A., Gurskiy S.I., Tomilova L.G., Zefirov N.S. Inorg. Chim. Acta 2010, 363, 1869-1878.

11. Dubinina T.V., Piskovoi R.A., Tolbin A.Y., Pushkarev V.E., Vagin M.Y., Tomilova L.G., Zefirov N.S. Russ. Chem. Bull. 2008, 57, 1912-1919. 
New Substituted Tetrathieno[2,3-b]porphyrazines

12. Abdurrahmanoglu S., Altindal A., Riza Ozkaya A., Bulut M., Bekaroglu O. Chem. Commun. (Cambridge, U. K.) 2004, 2096-2097.

13. Pushkarev V.E., Breusova M.O., Shulishov E.V., Tomilov Y.V. Russ. Chem. Bull. 2005, 54, 2087-2093.

14. Kobayashi N., Nakajima S.-I., Ogata H., Fukuda T. Chem.-Eur. J. 2004, 10, 6294-6312.

15. Linstead R.P., Whalley M. J. Chem. Soc. 1952, 4839-4846.
16. Martynov A.G., Zubareva O.V., Gorbunova Y.G., Sakharov S.G., Nefedov S.E., Dolgushin F.M., Tsivadze A.Y. Eur. J. Inorg. Chem. 2007, 2007, 4800-4807.

17. Zhu P., Pan N., Li R., Dou J., Zhang Y., Cheng D.Y.Y., Wang D., Ng D.K.P., Jiang J. Chem.--Eur. J. 2005, 11, 1425-1432.

18. Sheik-Bahae M., Said A.A., Wei T.-H., Hagan D. J., Van Stryland E.W. IEEE J. Quantum Electron. 1990, 26, 760-769.

19. Li C., Zhang L., Yang M., Wang H., Wang Y. Physical Review A 1994, 49, 1149-1157.

Received 08.06.2012

Accepted 18.06.2012 